\title{
SURVIVING OR FLOURISHING? INTEGRATING BUSINESS RESILIENCE AND SUSTAINABILITY
}

\begin{abstract}
:
Purpose

Businesses are always seeking resilient strategies so they can weather unpredictable competitive environments. One source of unpredictability is the unsustainability of commerce's environmental, economic or social impacts and the limitations this places on businesses. Another is poor resilience causing erroneous and unexpected outputs. Companies prospering long-term must have both resilience and sustainability, existing in a symbiotic state. This paper explores the two concepts and their relationship, their combined benefits and proposes an approach for supporting decision-makers to proactively build both characteristics.
\end{abstract}

\section{Design/methodology/approach}

The paper looks at businesses as complex adaptive systems, how their resilience and sustainability can be defined and how these might be exhibited. It then explores how they can be combined in practice.

\section{Findings}

The two qualities are related but have different purposes, moreover resilience has two major forms related to timescales. Both kinds of resilience are identified as key for delivering sustainability, yet the reverse is also found to be true. Both are needed to deliver either and to let businesses flourish.

\section{Practical implications}

Although the ideal state of resilient sustainability is difficult to define or achieve, pragmatic ways exist to deliver the right direction of change in organisational decisions. A novel approach to this is explored based on Transition Engineering and Robustness Engineering.

\section{Originality/value}

This paper links resilience and sustainability explicitly and develops a holistic pragmatic approach for working through their implications in strategic decision-making.

\section{Keywords:}

Sustainability, sustainable business, resilience, strategy, risk, adaptive capacity, flourishing, decision-making

\section{Article Classification:}

Conceptual

Sustainability is increasingly a strategic issue for firms seeking competitive advantage. It has been driven by stakeholder, legislative and cost changes, including natural resource constraints (Haanaes et al., 2012). Business resilience has also been of interest recently due to the unpredictable effects of globalisation and economic turbulence (Taleb, 2008) and in response to changing social limitations on, and expectations of, companies (Porter and Kramer, 2006). Usually resilience and sustainability have been examined as separate issues. This paper brings them together using a multidisciplinary approach and explores how they might be integrated into decisions to lead to flourishing rather than surviving businesses.

Senge (1993) described organisations as complex systems because they have many interacting feedback loops between their elements, interact with other complex systems, and produce non-linear, emergent behaviours. He compared them to living organisms which 
change and learn. Others have debated which system elements are key to delivering change, whether change is identical with learning and whether active management is required to cause them (Caldwell, 2012).

Writers on organisational sustainability have classified organisations as complex adaptive social systems, as change and learning happen within them (Polacek et al., 2012, Caldwell, 2012). They emphasise their need for effectiveness and adaptability in the face of increasingly complex and changing business contexts. Both qualities are needed to provide sufficient resilience for them to co-evolve with their environment (Hadders, 2011). Organisations are also sometimes called complex evolving systems, reflecting the idea that their identity might also change long-term (Mitleton-Kelly, 2003). The central argument of this paper is that for complex systems like companies to continue into the longest term, they must have the dual characteristics of resilience and sustainability rather than one or the other and that these two characteristics must exist in a symbiotic state.

This paper explores the concepts of resilience and sustainability in a business setting then the relationship between them, in order to explain why both are required for organisations to flourish rather than just survive. It concludes by discussing the practical implications of combining them and demonstrates how a decision-support approach based on engineering concepts can be used to offer practical solutions to complex business system problems.

\section{Resilience}

Common across many of the definitions of resilience is that it is a system quality. Its conceptual basis, derived mainly from ecology, is the ability of a complex system to return to stability after disruption (Bhamra et al., 2011). There are additional aspects to resilience concerning both the system's continued functionality during disruptions and its adaptation to environmental changes, whether innate or deliberate (Walker et al., 2002, Burnard and Bhamra, 2011, Wright et al., 2012). Resilience is needed by systems (and their elements) to cope with turbulent external environments ranging from smaller perturbations, to high impact events (Bhamra et al., 2011, Wright et al., 2012).

Approaches to developing system resilience have focussed on the reduction of uncertainty, risk and vulnerability. Uncertainty can be reduced by improving knowledge and therefore the ability to forecast the characteristics of disturbances, and risk by lowering the likelihood of specific events (Burnard and Bhamra, 2011). Vulnerability can be improved through mitigating the effect that disturbances have on the system by lowering its exposure to them, reducing its sensitivity to them, and increasing the system's range of available responses (Bhamra et al., 2011). Undesirable system behaviours can also be resilient (Walker et al., 2002, Wright et al., 2012) such as resistance to necessary change (Mamouni Limnios et al., 2013). A goal is needed for determining wanted and unwanted forms of resilience (Walker et al., 2002).

If the raison d'être for any business is the continued delivery of high quality benefits to its stakeholders (whether profits, status or reputation) then the ability to ensure not just survival, but a flourishing business quality of life, is key. In this sense resilience as a system quality enables the reliable delivery of goals regardless of circumstances. For a business resilience has much the same definition as for other systems, except proactive generation of 
sustainable competitive advantage is a particular goal (Burnard and Bhamra, 2011). Strategic resilience tends to favour diversification. Operational resilience, on the other hand, works well in unchanging conditions and favours specialisation and optimisation, yet both strategic and operational resilience are needed for success (Hamel and Välikangas, 2003a, Taleb et al., 2009).

Strategic resilience has been defined as "the ability to dynamically reinvent business models and strategies as circumstances change" (Hamel and Välikangas, 2003a, p.2). It is the capacity for firms do this continuously in anticipation of and not just in response to events, without causing themselves excessive disruption. This form of resilience ideally enables strategic renewal with "zero trauma" to the company, avoiding wasting precious resources and capacities and ultimately undermining competitive advantage. Strategic resilience also matters for the delivery of long-term goals and development of corporate efficiencies which require time to evolve (Hamel and Välikangas, 2003b).

Walker et al. (2002) developed three measures of general system resilience: first, how much change a system can withstand, without its functional control or structure changing; second, how much a system self-organises; both measure operations resilience for firms. Finally, there is the capacity for learning and adaptation a system expresses. This last is commonly termed adaptive capacity and can be further broken down into "learning, flexibility to experiment and adopt novel solutions, and development of generalised responses to broad classes of challenges" (Walker et al., 2002). This broadly matches the business-oriented definitions of strategic resilience elsewhere (e.g. Hamel and Välikangas, 2003a).

What fundamentally differentiates strategically resilient systems from irresilient ones is adaptive capacity. This ability to evolve new capacities and resources is the mechanism by which resilience is delivered (Burnard and Bhamra, 2011). Adaptive capacity can be improved by many different activities within a company and co-ordination of these is a strategic task (Parsons, 2010). A resilient business should proactively manage its adaptive capacity, and exhibit strategies which are proactive, efficient with resources, generate diversity, and based on realistic accurate assessments of itself and its context (Burnard and Bhamra, 2011, Hamel and Välikangas, 2003a, Bhamra et al., 2011, Hufschmidt, 2011).

Whilst there is disagreement as to exactly how vulnerability, resilience and adaptive capacity are conceptually related to each other, and whether each is tangible (Bhamra et al., 2011), there is agreement on the main processes which develop and deploy the adaptive capacity of any organisation. These are preparation, including the awareness of risks; planning and adapting in advance; mitigation through reacting to and overcoming an event in progress; and recovery by restoring efficacy and adapting after changes (Burnard and Bhamra, 2011, Hufschmidt, 2011, Bhamra et al., 2011, Wright et al., 2012).

Resilience and its components are not easy to measure from the outside. Organisational survival may be the proof of their presence but is retrospective and of limited help to business strategy. It is easier to assess future resilience as potential from within a company, where the components of adaptive capacity-building are more visible. These practices are of most use to a company's strategy-makers.

\section{Sustainability}


Sustainability is also a system quality (Fuller, 2012). The mainstream definition of sustainability as the triple bottom line aim of balancing different and sometimes conflicting goals is often shown as three circles with sustainability at their overlapping centre (e.g. Clift (1998) or Hart (1997)). Walker et al. (2002) summarise this as achieving "the continued wellbeing of the economy, society and natural resource base" (Walker et al., 2002, p.11). Brundtland's definition (1987) views sustainable development as a tool for achieving the goal of sustainability, but they are not identical concepts (Fuller, 2012). Sustainability theorists have developed these ideas further (Johnston et al., 2007), such as in the asset portfolio approach to natural resource management from Turner, built upon by Ross and Bissix with their exploitation paradigms (as summarised in Ewert et al., 2005, pp.160-163). These prioritise the generation or degradation of four capital types: (manufactured, natural, human and ethical) differently according to how they are valued.

Hart (1995) integrated natural resources into the existing resource-based theory of the firm. He argued that competitive advantage could only be maintained by considering natural resources as vital to success as more traditional resources (e.g. capabilities such as innovation or brand differentiation), and that proactive natural resource management offers opportunities for firms rather than just reactive solutions to existing problems (ibid.). Rockström et al.'s (2009) assessment indicates that several planetary natural resource systems required for human life require restoration whilst others will soon reach their limits. This has important implications for businesses as it causes supply-side shortages of resources, shifts in market attitudes plus increasing legislation imposed to limit negative environmental impacts (see e.g. PwC, 2011), and their joint corollary of limits to economic growth and therefore profitability. Jackson (2009) argues that these limits will become tighter over time and can only be overcome by being more efficient with resources and rebuilding natural capitals. Porter and Kramer (2011) also recommend companies internalise wider social and environmental goals, to overcome these limiting issues and find new sources of competitive advantage. This allows the creation of "shared value" for business and society and avoids them becoming two sides of a trade-off (ibid.).

Businesses are elements within an economic ecosystem which operates within the larger system of human society, which is in turn contained within the planetary environment. Each business impacts upon, and is impacted by, issues differently depending on how it uses, wastes or pollutes resources such as materials, or energy. It is also impacted by the surrounding system of other organisations and individuals which form its supply chain, markets and stakeholders. Individual businesses, like species within ecosystems, transform resources from some kinds of capital to others for human benefit (Ewert et al., 2005 p.160). It is impossible for one business to have a positive effect on all capitals, so other elements are needed to create a system that recycles and transforms resources as efficiently as possible back the other way to operate as sustainably as possible. However businesses can improve the balance of their positive and negative impacts, and this forms the basis of a clear definition of sustainability for their uses.

Johnston et al. use the science-based principles of The Natural Step approach (TNS) to derive their own definition of operational sustainability for organisations, based on eliminating organisational contributions to ecological and social ills. The TNS approach also fits well with the natural resource-based view of the firm from Hart (1995). For the purposes 
of this paper, therefore, the following general definition of business sustainability is used, based on Johnston et al. (2007):

A firm pursuing sustainability will seek to eliminate the negative impacts and improve the positive impacts from its activities, to restore natural capital whilst enhancing human and maintaining ethical capitals. It will do this by eliminating resource extraction and pollution, identifying unsustainability risks and opportunities, prioritising them on their net contribution to the capitals and mitigating such risks or exploiting opportunities, whilst maintaining economic capital so as to operate long term.

There is still debate about how to define and measure sustainability, how much change is needed, what is to be done and by whom. Krumdieck (2011a) acknowledges this and identifies a pragmatic solution; treat the problem as you would safety. It is almost impossible to define or deliver a completely safe system, but we do know what unsafe systems look like and how they can be improved. Krumdieck suggests that we can already measure and therefore work away from unsustainability, through a process of identification, prioritisation and mitigation. Both safety and sustainability assessments vary with location and context, and require prioritisation between different kinds of risks; those which cannot be removed or mitigated require adaptation to reduce the system's vulnerability to their impacts (ibid.). That adaptation is part of the management of resilience as mentioned earlier.

\section{Linking Sustainability and Resilience for Businesses}

. Given the ecological and social scientific origins of the concepts of sustainability and resilience, the logical starting point for a discussion of their relationship in an organisational context is that both consider the continuity of function of an active system. A resilient system that works well should be more sustainable because it can operate better for longer. This fits well with resilience theory's emphasis on high quality performance. Walker et al. (2002) propose sustainability as the goal which can be applied to evaluate and steer the development of resilience.

The process of improving sustainability occurs in a complex dynamic setting, requiring constant adjustment to boundaries, goals and functions; needing the adaptive capacity which comes from strategic resilience. Unsustainability causes external input-side issues for a company as we have already seen through feedback mechanisms from its own impacts and others', requiring more of both kinds of resilience; unsustainability can also underlie internal inefficiencies, for example of raw material use. Lack of resilience leads to degraded quality in company outputs, which may also cause inefficient use of internal resources and therefore the longer term sustainability of business performance is lessened including its economic viability.

If improved sustainability must be the ultimate and always moving goal defining the direction of travel, then resilience is the ability not to be pushed off course along the way and adapt to that changing goal. Conversely sustainable organisations actively reduce their risks and vulnerability, create better value for a society beset by limits and problems, and have more ability to exploit new "ecosystem" opportunities, which further improves their resilience. Turbulent business conditions will also require more of both qualities to maintain 
the same performance. Flourishing organisations therefore need to have both resilience and sustainability.

Different organisations can have different capacities to be sustainable or resilient and individually their capacity for both will fluctuate over time. Not all sustainability problems are slow; if unsustainability causes systems to become more unstable, then sudden and unexpected shocks are more likely. Meanwhile neglecting to build long-term resilience limits available strategic options, no matter how nimble the company. The dividing-line between short and long-term versions of both concepts is blurry and in reality the classification of individual challenges as sudden disruption or slower impact will depend on the company's time horizons. We propose that operational resilience is needed to deliver short-term sustainability, strategic resilience is required for longer-term sustainability (and vice versa), and that flourishing organisations need a proactively managed blend of both qualities across these different timespans. Without this combination firms will be vulnerable to factors which pose risks to their continuity. A sustainable firm concentrating on strategic resilience can cope with long-term shifts through corporate strategy (Aggerholm et al., 2011) and collaboration with stakeholders (Lozano, 2008), but will be vulnerable to immediate significant shocks to which they cannot respond. A firm focussing on operations resilience and short-term sustainability, suffers vulnerability from a lack of awareness of longer-term structural changes in the environment. Organisations with such short-term resilience simply survive unexpected events, work hard in order to stand still by generating a series of nimble responses to shorter-term disruptions, and rely on their "speed and capability" (Brunsdon and Dalziell, 2005, p27).

Balancing appropriate levels of seeming conflicting adaptation with efficiency can be resolved by considering the desirability of the business' function (Mamouni Limnios et al., 2013), leading back to sustainability as a goal of resilience (Walker et al., 2002). Figure 1 below offers a matrix inspired by Mamouni Lminios et al. (2013) which combines temporal levels of sustainability and resilience in a series of organisational types. Organisations will have a blend of sustainable and resilience characteristics at any point in time and their ability to continue to function will be determined by this blend of resilient sustainability. 


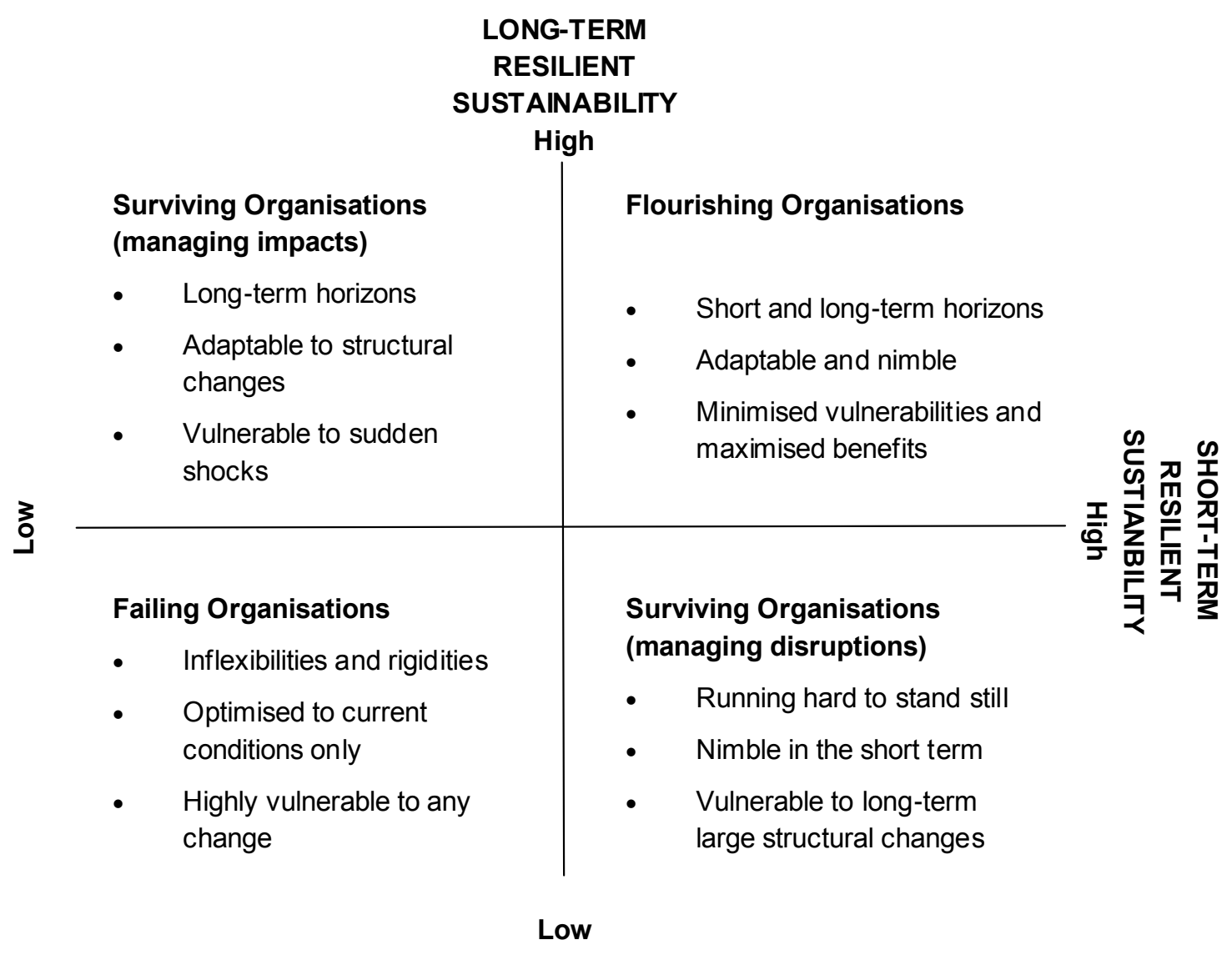

Figure 1: Different Organisational Blends of Resilience and Sustainability

Our argument is that for organisations to flourish, they need to have high levels of both types of resilience and sustainability as, in an uncertain world, this is the only way in which vulnerabilities can be minimised and continuity of high quality performance be assured. Organisations with low levels of resilient sustainability are inevitably doomed to failure given their overly inflexible yet vulnerable nature, whereas organisations with one or the other are, albeit in different ways, simply surviving; but in a way that will always be risky.

\section{Resilient sustainability in practice}

The premise of this paper is that resilience is primarily concerned with flourishing survival and actions which the company itself takes, and closely allied to the goals of businesses. Due to its interdependent links with sustainability it can be used to translate sustainability thinking for business decision-makers into practical approaches for delivering real strategic and competitive advantage. It allows sustainability to be framed as minimising risks and exploiting opportunities both long and short-term, in a way directly relevant to executive officers and therefore also more likely to be acted upon.

Companies make strategic assessments about which choices will reduce uncertainty, risk, and vulnerability; in essence seeking to improve resilience (Burnard and Bhamra, 2011, Bhamra et al., 2011). Whilst limited data can be gathered, there will always be unpredictable high-impact low-probability events to contend with: "Black Swan events don't 
have precedents" (Taleb et al., 2009, p.79). We can however concentrate on the consequences of challenges to the company instead of trying to identify all their causes, and use robust systems design as a part of strategic resilience development to remove unnecessary risks and reduce vulnerability. Some events and even solutions will always lie outside a company's capacity to influence and these remaining disruptions are where operations resilience will need developing (Burnard and Bhamra, 2011), (Taleb et al., 2009) and (Hufschmidt, 2011).

Resilient companies cannot accommodate every possible disruption into their strategic thinking and solve all their unsustainability issues at the same time. Clearly, this is a strategic impossibility because the issues are large and interconnected. A pragmatic framework is needed to help managers sort through the issues and opportunities, to identify the key interventions and prioritise their efforts (Pugh and Bourgeois III, 2011). This requires a system model, and a method for effecting change. Businesses are complex social systems and each is unique, so this cannot be a prescriptive one-size-fits-all approach; it must be generic and flexible. It also needs to be capable of working at different levels within and even beyond individual firms, wherever a strategy decision might be encountered.

\section{A new approach}

As strategic sustainability and resilience have historically developed separately, a fully developed approach that integrates the two for business purposes is lacking. The approaches of most interest are Creating Shared Value (CSV; Porter and Kramer, 2011) and Transition Engineering (TE; Krumdieck, 2011b). CSV is a work-in-progress concentrating on strategic sustainability goals supporting business growth and performance, but lacks detail around the process of making decisions (Porter and Kramer, 2011). TE is also still developing, and seeks to increase systems resilience and sustainability but springs from systems engineering not business, relying on other engineering techniques for users to structure the information about their system (Krumdieck, 2011b). Both are intended specifically to tackle unsustainability and irresilience for multiple stakeholders. Due to this compatibility, they can be usefully combined to provide a new framework for effecting change in businesses.

However the generic process is still missing for creating and using a system model of the organisation, product-service system or even business model which is subject to the strategic decision. Engineering companies will often use well-established tools based on Taguchi's Quality Design, particularly Failure Mode Avoidance (FMA) and Robustness Engineering Design (RED) to design resilient performance into a complex system and avoid failures. In RED, once the ideal function of a system is decided and its most critical parameters identified, "Parameter Design" is used to optimise its resilience, leading to improved performance against costs (Kolarik, 1995, p113). This is compatible with Transition Engineering's dual focus on resilience and avoiding sustainability failures (Krumdieck, 2013) and the focus within business on desirable performance as opposed to inefficiencies and negative impacts. Whilst a full-blown use of RED would not be possible due to the lack of precise information available, we argue that a simplified version of its systems analysis can be used within the new combined approach. 
Within RED the creation of a Parameter Diagram is key (Karna and Sahai, 2012), capturing the many inputs potentially affecting the system, information about its complex functions, how they are controlled, and its resulting simultaneous delivery of various desirable and undesirable outputs. This allows optimisation of control factors which affect the system's functions, or even redesign of the system. This approach can even be used with conceptual designs with little quantitative information; and in the authors' experience is so flexible and useful that industrial managers sometimes use it for analysing business processes.

RED can also be used to relate sustainability and resilience practically, by considering unsustainability as both an unwanted input to, and output of, the company's complex system and a source of internal inefficiencies; in effect as a form of cost. The traditional financial cost (effectively an unwanted outcome to be minimised) can be widened to include the undesirable social and environmental costs of a system. Optimising the system's function to improve sustainability and creating the required resilience to both reduce and cope with unsustainabilities becomes the objective of the design process.

Figure 2 shows such a Parameter-diagram of a simplified model of a manufacturing company. The desirable outputs produced by the system include social and environmental benefits as well as financial, to other stakeholders besides customers. These benefits and related degradations from the undesirable outputs together impact the various capital types previously mentioned.

Figure 2- adapted Parameter diagram for a manufacturing company

Some versions of RED distinguish signals (inputs which the system is intended to convert into desired outputs) from noises (inputs which are not intended to be responded to as they

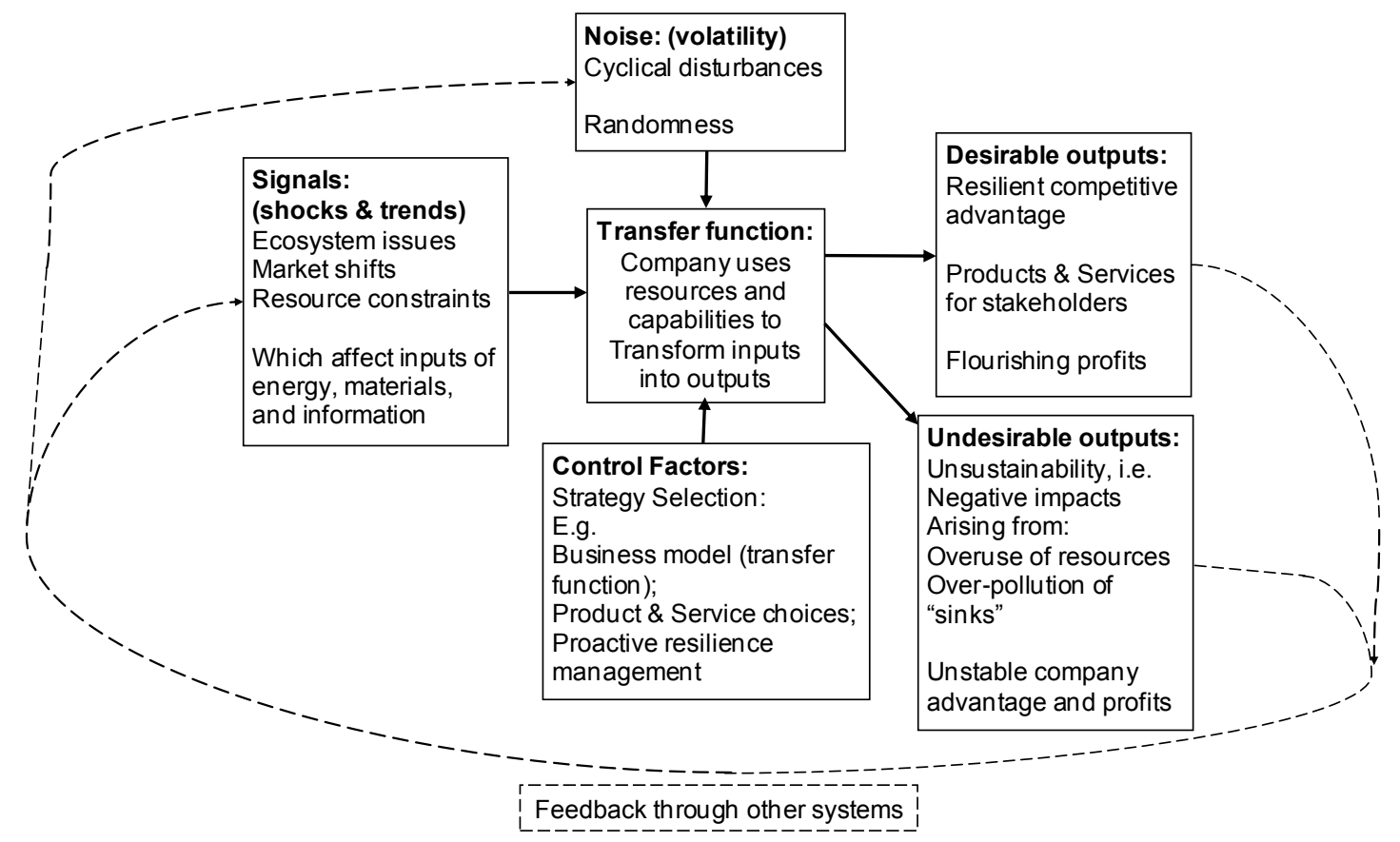

lead to undesirable outputs). Inputs are mostly beyond the company's control, except in their selection during the functional design. Outputs are driven by its activity or transfer 
functions, and its choice of strategic and operational goals- the "settings" of the control factors. In any such Parameter diagram only these control factors and the system transfer functions can be influenced by the company; and this is where any improvements in resilience must be created.

Figure 2 also shows a system producing Porter and Kramer's "Shared Value" (2011). This value-based view can be used to ensure that all the significant effects of the system on multiple stakeholders are considered, to ensure that the balance of negative to positive impacts is optimised.

This Robustness Engineering approach however typically does not lead to explicit assessments of resilience except in industries which already define and measure this. So we must look back to Transition Engineering for tools to integrate resilience thinking and adaptive capacity assessments into decisions.

Krumdieck's TE approach (2011b) concentrates on risks to system function, but can also be applied to opportunities, which is useful for business users. Either challenge type can be inserted into this approach as signals, as solution options; or as outputs depending on how the system and its functions are defined (ibid.). Transition Engineering also contains simple approaches for scenario generation, and an assessment framework for testing and selecting options against these scenarios (ibid.) which can be adopted for more generic use. This includes adaptive capacity assessments which prompt users to look for the widest resilience to a number of future scenarios. Vulnerability assessments to identify risks can combine design risk-management methods from RED, and those from TE which resemble natural hazard vulnerability assessments. Figure 3 shows the approach; the Parameter Diagram is core to the whole and dominates the "Assess System" phase particularly. The process resembles a Deming cycle (Arveson, 1998) in its stages and in that users may enter the process at any point. 


\section{Disruption \& change sources}

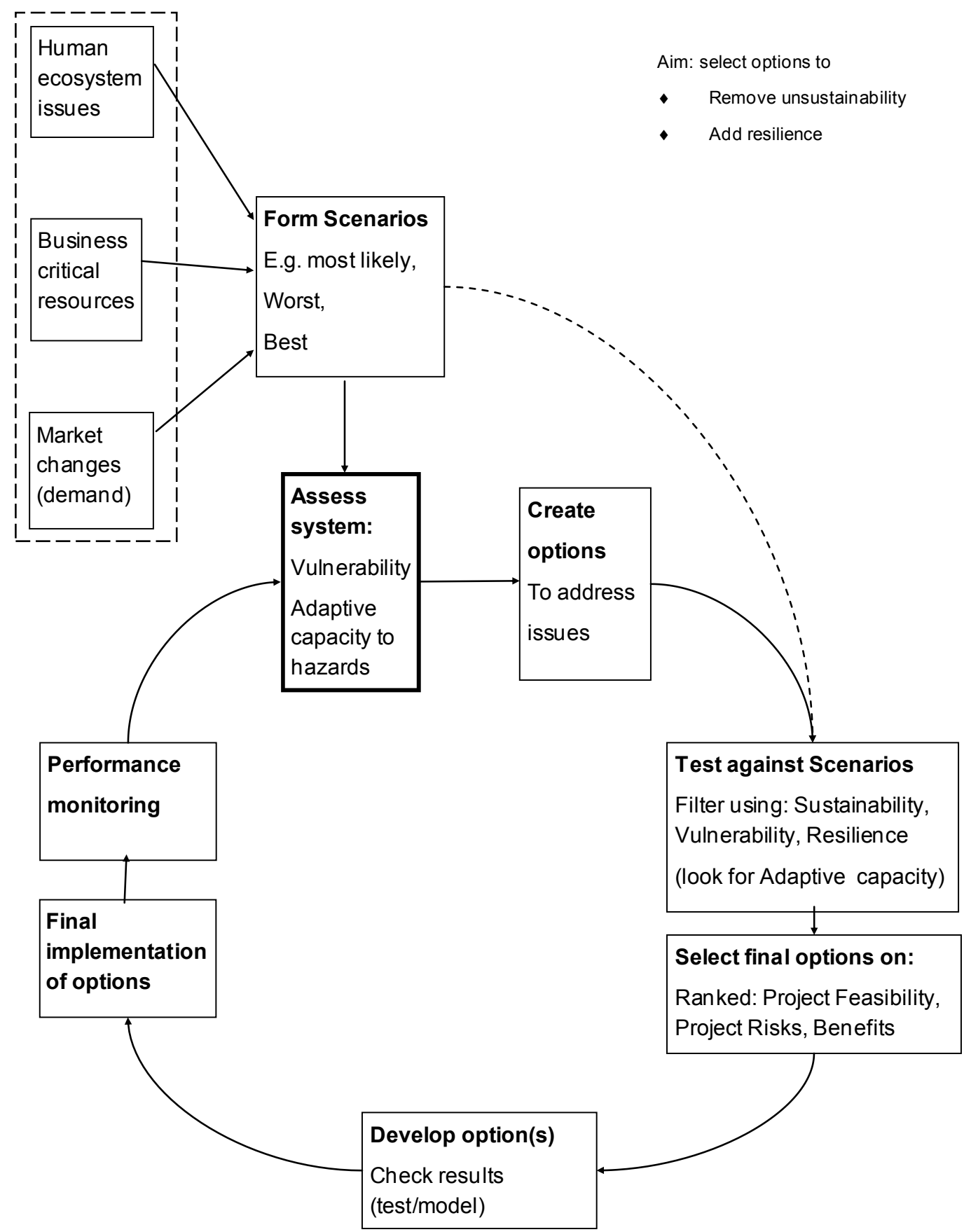

Figure 3- simple process flow for Resilient Sustainability approach

Every company (and product) will have its own individual risk profile which is dictated by differences in vulnerability, exposure, adaptive capacity and sustainability. It will also have its own feasibility profile for solutions, driven by internal capabilities and resources. Prioritising the intersection of the highest priority risks with those solutions which the company can best influence (Hamel and Välikangas, 2003a) allows the selection of the biggest strides away from unsustainability and irresilience (Krumdieck, 2011a). 


\section{Summary}

The proposed Resilient Sustainability approach offers the prospect of translating a more general sustainability issue into practical assessments of risks and solutions which help managers prioritise between different options. Options are sought which specifically reduce system vulnerability and improve adaptive capacity, by testing them against a set of future scenarios, to identify those with the best combination of broad resilience across all outcomes, project feasibility and risk (Krumdieck, 2011b). This improves both the business system design and the range of strategies available for coping with change, enhancing both kinds of resilience. It therefore also supports the delivery of improved sustainability.

This generic and complete combination of strategic analysis and engineering thinking to address resilience and sustainability together and support decision-makers with better integrated information is novel. Moreover it allows the potential selection of a suite of solutions rather than just one over-optimised one. In strategy terms this follows Hamel and Välikangas' (2003a) advice to have many small strategic experiments in progress.

As the relationship between resilience and sustainability is theoretically robust and, it is also likely to be empirically robust and practically useful. The next phase of this research will be to test the approach inside a host organisation to discover whether it is indeed useful for analysing and improving the sustainability and resilience of organisations, and to refine it further.

\section{References}

AGGERHOLM, H. K., ANDERSEN, S. E. \& THOMSEN, C. 2011. Conceptualising employer branding in sustainable organisations. Corporate Communications: An International Journal, 16, 105-123.

ARVESON, P. 1998. The Deming Cycle [Online]. Cary, NC, USA: The Balanced Scorecard Institute: Strategy Management Group. Available: http://www.balancedscorecard.org/thedemingcycle/tabid/112/default.aspx [Accessed 29th Aug 2013].

BHAMRA, R., DANI, S. \& BURNARD, K. 2011. Resilience: The concept, a literature review and future directions. International Journal of Production Research, 49, 5375-5393.

BRUNDTLAND, G. H. 1987. World commission on environment and development. Our common future, 8-9.

BRUNSDON, D. \& DALZIELL, E. 2005. Making Organisations Resilient: Understanding the Reality of the Challenge. CAE: Resilient Infrastructures Conference. University of Canterbury, New Zealand.

BURNARD, K. \& BHAMRA, R. 2011. Organisational resilience: Development of a conceptual framework for organisational responses. International Journal of Production Research, 49, 5581-5599.

CALDWELL, R. 2012. Systems Thinking, Organizational Change and Agency: A Practice Theory Critique of Senge's Learning Organization. Journal of Change Management, $12,145-164$. 
CLIFT, R. 1998. Engineering for the Environment: The New Model Engineer and her Role. Process Safety and Environmental Protection, 76, 151-160.

EWERT, A. W., BAKER, D. C. \& BISSIX, G. C. 2005. Integrated Resource and Environmental Management : The Human Dimension, Cambridge, MA, USA, CABI Publishing.

FULLER, R. J. 2012. Beyond cliché-reclaiming the concept of sustainability. Australian journal of environmental education, 26, 1-12.

HAANAES, K., REEVES, M., VON STRENG VELKEN, I., AUDRETSCH, M., KIRON, D. \& KRUSCHWITZ, N. 2012. Sustainability Reaches a Tipping Point. MIT Sloan Management Review Research Reports. North Hollywood, California, USA: MIT (Massachusets Institute of Technology) Sloan Management Review and BCG (Boston Consulting Group).

HADDERS, H. 2011. The Adaptive Quadruple Bottom Line Scorecard: Measuring organizational sustainability performance.

HAMEL, G. \& VÄLIKANGAS, L. 2003a. The Quest for Resilience. (cover story). Harvard Business Review, 81, 52-63.

HAMEL, G. \& VÄLIKANGAS, L. 2003b. Why Resilience Matters. (cover story). Harvard Business Review.

HART, S. L. 1995. A Natural-Resource-Based View of the Firm. The Academy of Management Review, 20, 986-1014.

HART, S. L. 1997. Beyond Greening: Strategies for a Sustainable World. Harvard Business Review, 75, 66-76.

HUFSCHMIDT, G. 2011. A comparative analysis of several vulnerability concepts. Natural Hazards, 58, 621-643.

JOHNSTON, P., EVERARD, M., SANTILLO, D. \& ROBÈRT, K. H. 2007. Reclaiming the definition of sustainability. Environmental Science and Pollution Research, 14, 60-66.

KARNA, S. K. \& SAHAI, R. 2012. An Overview on Taguchi Method. International Journal of Engineering and Mathematical Sciences, 1, 11-18.

KOLARIK, W. J. 1995. Creating quality: concepts, systems, strategies, and tools, Singapore, McGraw-Hill Book Co.

KRUMDIECK, S. 2011a. The Survival Spectrum: The Key to Transition Engineering of Complex Systems. Proceedings of the ASME 2011 International Mechanical Engineering Congress \& Exposition, IMECE2011. Denver, Colorado, USA: University of Canterbury, New Zealand.

KRUMDIECK, S. 2011b. Transition Engineering Of Urban Transportation For Resilience To Peak Oil Risks. Proceedings of the ASME 2011 International Mechanical Engineering Congress \& Exposition, IMECE2011. Denver, Colorado, USA: ASME.

KRUMDIECK, S. 2013. Transition Engineering: Planning and Building the Sustainable World. The Futurist (online), 47. 
LOZANO, R. 2008. Developing collaborative and sustainable organisations. Journal of Cleaner Production, 16, 499-509.

MAMOUNI LIMNIOS, E. A., MAZZAROL, T., GHADOUANI, A. \& SCHILIZZI, S. G. M. 2013. The Resilience Architecture Framework: Four organizational archetypes (Article in Press). European Management Journal http://dx.doi.org/10.1016/..emi.2012.11.007.

MITLETON-KELLY, E. 2003. Ten principles of complexity and enabling infrastructures. Complex systems and evolutionary perspectives on organisations: The application of complexity theory to organisations. 1st ed. Oxford, UK: Elsevier Science Ltd.

PARSONS, D. 2010. Organisational resilience: Parsons argues that a modern organisation's ability to survive and prosper against the flow-on effects of natural disasters will depend on its resilience capacity. Australian Journal of Emergency Management, 25, 18-20.

POLACEK, G. A., GIANETTO, D. A., KHASHANAH, K. \& VERMA, D. 2012. On principles and rules in complex adaptive systems: A financial system case study. Systems Engineering, Early View (Online version of record published before inclusion in an issue), $\mathrm{n} / \mathrm{a}-\mathrm{n} / \mathrm{a}$.

PORTER, M. E., HILLS, G., PFITZER, M., PATSCHEKE, S. \& HAWKINS, E. 2012. Measuring Shared Value: How to unlock value by linking social and business results. FSG Knowledge Exchange Articles. Boston, MA, USA: FSG.

PORTER, M. E. \& KRAMER, M. R. 2006. Strategy \& Society: The Link Between Competitive Advantage and Corporate Social Responsibility. Harvard Business Review, 84, 7892.

PORTER, M. E. \& KRAMER, M. R. 2011. Creating Shared Value. Harvard Business Review, $89,62-77$.

PUGH, J. \& BOURGEOIS III, L. J. 2011. "Doing" strategy. Journal of Strategy and Management, 4, 172-179.

PWC 2011. Minerals and metals scarcity in manufacturing: the ticking time bomb. Sustainable Materials Management. London, UK: PwC (formerly Price Waterhouse Cooper).

TALEB, N. N. 2008. The black swan: the impact of the highly improbable, London, UK, Penguin Books Ltd.

TALEB, N. N., GOLDSTEIN, D. G. \& SPITZNAGEL, M. W. 2009. SPOTLIGHT ON RISKThe six mistakes executives make in risk management. Harvard Business Review, 87, 67-67.

WALKER, B., CARPENTER, S., ANDERIES, J., ABEL, N., CUMMING, G., JANSSEN, M., LEBEL, L., NORBERG, J., PETERSON, G. D. \& PRITCHARD, R. 2002. Resilience Management in Social-ecological Systems: a Working Hypothesis for a Participatory Approach. Conservation Ecology, 6.

WRIGHT, C., KIPAROGLOU, V., WILLIAMS, M. \& HILTON, J. 2012. A Framework for Resilience Thinking. Procedia Computer Science, 8, 45-52. 
